THE brief flight of Soyuz-15 (August 26-28) has led to considerable speculation as to some possible failure which may have led to its curtailment. The report of a naked-eye sighting of Soyuz-15, which at 4.30 a.m. (GMT) on August 28 was seen to have overtaken the orbiting space-station Salyut3 , suggested that something had gone amiss, preventing an intended docking of the two craft.

In fact, however, the official Tass reports do little to substantiate these speculations. Although the first statement does mention Salyut-3 it does so only in an oblique manner, stating that: "The purpose of the launch of Soyuz-15 is the continuation of the scientific research and experiments in outer space begun on July 3 of this year in the flight of the transport ship Soyuz-14 and the station Salyut-3". The mention of Salyut-3 certainly suggested that the two craft would, in some way, participate in a joint experiment; the next Tass release, however, stated clearly that this would not be a link-up. The experiements were intended "to work out techniques of piloting the craft in different regimes of flight. In the process of manoeuvering the craft, Soyuz-15 made a number of approaches to the Salyut-3 station. The cosmonauts controlled the operation of all systems of the ship, carrying out observations of the stages of approach to the station". Soyuz-15, the release continued, was now preparing to return to earth.

The Tass account of the descent stressed the details of the flight procedure-the use of the braking motors to align the craft before descent, the release of the parachute system and the firing of the braking motors immediately before touchdown. The aim of this last stage of the experiment was to test "methods and means of and uncommunicative, frustrating the finding and evacuating a spaceship desire for further information with

\section{Soyuz - 15: didn't fall, wasn't pushed}

from Vera Rich

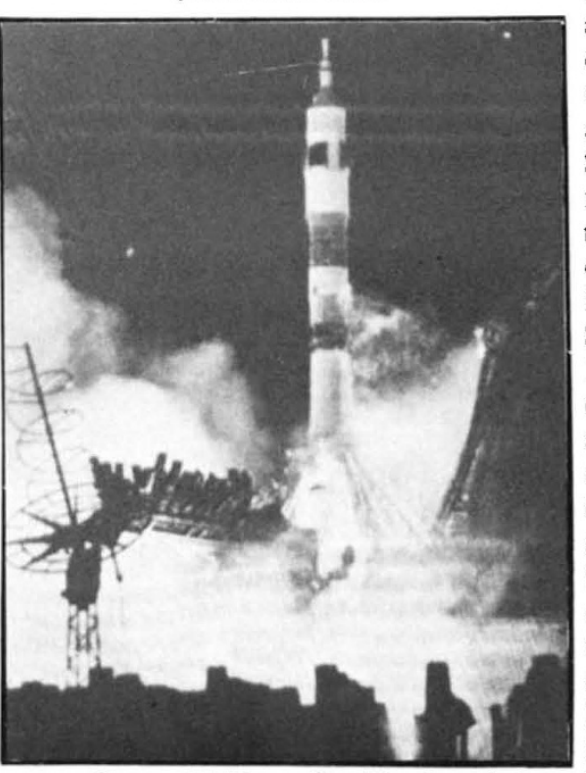

Soyuz-15 blast-off: AP wire picture.

which had landed in night conditions", This was the first true night landing, although Soyuz-10 landed in predawn conditions. The search and recovery stage of Soviet space ventures has always held its own special hazardsone early pair of cosmonauts had to fight their way back to civilisation through the snow for two days Nevertheless, according to V. A. Shatanov, the commander of Soyuz-10, the need to practise night-landing is becoming more and more necessary, since the necessity to land at a given time of day imposes rigid conditions on the flight-plan even before take-off. Tass reports are traditionally brief such phrases as "according to its assigned programme", or "carricd out its aims", without specifying full details of that programme or those aims. They are in a style therefore admirably suited to effect a cover-up of a partially aborted programme. But what if the speculations are wrong, and there was no break-down, and Soyuz-15 was planned from the beginning as a two-day mission. The need to practise night-landing, thereby eliminating rigidity of the flight plan, fits in well with the plans for the joint Soyuz-Apollo programme planned for 1975. (There could be considerable loss of face if either party had to ask for a revision of the joint flight-plan because its crew and ground support could not manage a landing under such-and-such conditions!) The practice of docking approaches from various positions, and the insistence that the cosmonauts were in total control of the craft is also interesting. There has always been a tendency in the Soviet manned space programme to incorporate a certain amount of ground control - the early cosmonauts were little more than passengers in the craft that carried them.

Speculation has suggested some technical failure in the Soyuz-15 craft, with possible setbacks to the SoyuzApollo programme. This may be the true explanation-but there remains the possibility that he Tass statements, do give, albeit briefly, the real objectives of the mission; that the flight of Soyuz-15 was intended simply to test out tricky manoeuvres, so that, in the joint mission, Sovict prestige might be duly maintained, by Soviet cosmonauts able to perform their part of the mission even in adverse circumstances-making docking approaches from any position, and able to cope with a touchdown at any hour of the day or night. have to find some kind of subvention to enable the company to remove the one mile existing track. There are two further miles of track in the form of unassembled beams in store at the manufacturers. What is to be done with them? With THL in nominal existence only, how are the numerous patents and the accumulated expertise to be exploited? It is impossible that the last has been heard of the tracked hovercraft and its company. Professor Laithwaite and his magnetic river are probably its greatest 'liquid' asset. $\mathrm{He}$ has not been heard from since the White Paper's publication but it is understood that alternative support is under discussion for the track and the plan to make it part of a possible joint European rapid transit centre.
There is a meeting of the EEC intercity working party in October in which ex-THL staff take part. The Select Committee may be regretting the move which enabled the Government to publish its meagre response while Parliament was in recess. This does not reflect on the excellence and thoroughness of the Committee's original Report and inquiry and there must be every expectation that it will cither call for more evidence or make its views known through a debate on the White Paper as soon as Parliament is reconvened possibly accompanied by a further publication.

As to the sorry tale of the hovertrain's relevance for the bigger issuc of the proper support of innovation today, Sir Christopher Cockerell, in- ventor of the parent concept, the hovercraft, gives the best summary (in a Memorandum to the Select Committec):

"To carry through a major development, a powerful lobby is required example, Concorde; or a very powerful position - example British Rail and the high speed train: or prestige and many jobs at stake-example, Rolls Royce and the RB 211... Now consider a brand new idea. It starts with neither money, facilities, a proven performance, a proven market, a lobby, prestige, johs at stake, nor even people who understand it. . . What is missing for hig projects is a suitable machincry to cover the stages between NRDC's limited support and the fully commercial stage". 